\title{
Perspectives
}

\section{Chagas and health promotion: dialogue inspired by the Curitiba Statement}

\author{
Mariana Sanmartino ${ }^{1, *}$, Andrea Avaria Saavedra ${ }^{2,3}$, Jordi Gómez i Prat ${ }^{4}$, \\ and Pedro Albajar-Viñas ${ }^{5}$
}

${ }^{1}$ Grupo de Didáctica de las Ciencias, Instituto de Física de Líquidos y Sistemas Biológicos (Consejo Nacional de Investigaciones Científicas y Técnicas-Universidad Nacional de la Plata), La Plata, Buenos Aires, Argentina, ${ }^{2}$ Escuela de Trabajo Social, Núcleo Diversidad, Facultad de Ciencias Sociales y Humanidades, Universidad Autónoma de Chile, Santiago, Chile, ${ }^{3}$ FONIS SA18I0056, Fondecyt 3160106, Programa Interdisciplinario de Estudios Migratorios (PRIEM), Universidad Alberto Hurtado, Santiago, Chile, ${ }^{4}$ Unitat de Medicina Tropical i Salut Internacional Vall d'Hebron-Drassanes, Programa de Salut Internacional de I'ICS (PROSICS), Barcelona, Spain and ${ }^{5}$ Programme on Control of Chagas Disease, Department of Control of Neglected Tropical Diseases, World Health Organization, Geneva, Switzerland

*Corresponding author. E-mail: mariana.sanmartino@conicet.gov.ar

\section{Summary}

With the objective of providing an insightful analysis of Chagas disease in the world, the authors share their collective reflections about the current situation of this public health problem in: rural environments of Latin America; urban environments of endemic and non-endemic areas everywhere; and, at a global level. A perspective based on the 'Democracy and Health Promotion' axis allowed the development of an innovative update about Chagas disease as a model of a complex socio-environmental health problem, with a key set of elements that goes beyond biomedical aspects. The authors created a dialogue between the fundamental elements of the Curitiba Statement on Health Promotion and Equity and crucial aspects of a reflection on the reality of Chagas disease today that at the same time challenges the different actors involved. With that reference, the call to promote a 'critical analysis of viabilities and opportunities for action, considering the potentialities and barriers imposed by the complexity of social movements in the present context of recedes and the loss of rights' was emphasized repeatedly. Finally, on the occasion of the recent creation of the Technical Group on Information, Education and Communication to control Chagas disease, WHO Department of Control of Neglected Tropical Diseases, the authors share reflections to propose an inclusive and transformative approach of health promotionwhat we hope is a new horizon for people affected, directly and indirectly, by Chagas disease.

Key words: Chagas disease, Curitiba Statement, community health promotion, determinants of health, global health 


\section{INTRODUCTION}

In the analysis of the link between democracy and health promotion, the consideration of human rights becomes inescapable. In addition to the 25th article about health of the United Nations (UN) Universal Declaration of Human Rights itself, the right to health is essential in order to exercise other rights related to life, territory, food, housing, work and education, among others. It is an inclusive right that exists beyond healthcare, referring to the necessity of community knowledge and values, the guarantee of other health determinants, such as access to drinking water, and necessary actions to prevent diseases.

Democracy is the ideal institution in order to guarantee respect for human rights and health promotion as an essential factor that will strengthen the foundations of the right to health, as understood in an inclusive sense. Consequently, health promotion calls for the strengthening of community action in setting priorities, taking decisions and defining, planning and implementing strategies to achieve the highest possible level of health. It transcends the idea of healthy lifestyles, including health conditions/requirements, such as peace, housing, education, food, income, resources and ecosystem sustainability, social justice and equity (Galvez and Irazola, 2006).

On the other hand, the endorsement by the UN Member States of the Sustainable Development Goals (SDGs), in September 2015, included neglected tropical diseases (NTDs) as one of the targets for integrated global action for the first time. This inclusion represents a unique opportunity to strengthen the agenda of control of these diseases representing a significant public health problem throughout the world (Ramos and Sousa, 2017). We agree with Mitra and Mawson when they point out that in addition to their impact on health, NTDs contribute to an immense social and economic burden resulting from social stigma, physical disabilities, disfigurement, blindness, discrimination, loss of social status, malnutrition, growth failure and impaired cognitive development. In that framework, Chagas disease, a typical NTD, is a paradigmatic example to analyse the previously mentioned elements (Mitra and Mawson, 2017).

Chagas disease is caused by the protozoan parasite Trypanosoma cruzi. The World Health Organization (WHO) estimates that about eight million people are infected, principally in the 21 Latin American continental countries, in what is called the 'endemic area' for Chagas. Moreover, it is estimated that $>10000$ people die annually due to the disease (WHO, 2010,
2013). The infection is mainly transmitted through the faeces/urine of hematophagous triatomine bugs (vectorial transmission), known as 'vinchucas', 'chinches', 'barbeiros' or 'kissing bugs' (among many other names, depending on the geographical area). The infection can also be transmitted by: infected women during pregnancy or at birth (congenital transmission); blood transfusions or organ transplantation from infected donors; and through the ingestion of food contaminated with the faeces/urine of infected triatomines. Although $>50 \%$ of people with infection present no symptoms, it is estimated that $1 / 3$ of them will develop cardiac, digestive, neurological or mixed clinical manifestations. Alternately to the biomedical denomination of 'Chagas disease', throughout this article we will refer, as well, to 'Chagas', with a broader meaning to include also the psychological and socioeconomic problematic that affects people infected by $T$. cruzi (most of whom will never develop the disease), their relatives and societies.

Due to its extent and consequences, it has been considered one of the most important public health problems in Latin America. At the same time, the growing mobility of the population has modified its epidemiologic characteristics (Coura and Viñas, 2010; VelardeRodríguez et al., 2010; Basile et al., 2011) and currently it is predominantly urban $(2 / 3$ of the infected people live in urban areas)-but still a rural problem in endemic countries-and also found in other continents (Coura and Viñas, 2010).

In that scenario, one of the principal challenges for health systems is underdiagnosing of the disease. Worldwide, it is estimated that $<10 \%$ of people carrying the T. cruzi infection know their condition and, consequently, a large number of individuals do not look for adequate healthcare (WHO, 2010, 2013, Basile et al., 2011). In addition to these frequently recognized healthcare barriers, three additional challenges are repeatedly identified: the mobility of the affected population mainly by reason of job search; the challenge to recognize, diagnose and take care of infected individuals in non-endemic areas where the disease is unknown; and, the irregular or 'illegal' condition of affected people jeopardizing the access to health systems.

Due to all factors involved, the authors defend that speaking about 'Chagas' is much more than speaking about a disease. The fact of recognizing the biomedical, epidemiologic, sociocultural, political and economic aspects of its complexity, makes the approaches of research, prevention, control and care that offer comprehensive answers in accordance with the particularities of 
current scenarios necessary (Sanmartino et al., 2015a), specifically in the globalization era.

Two challenges highlighted in the present context are: to avoid situations and processes in which the disease leads to exclusion and stigmatization; and to actively demystify fatalistic disease visions that entail and paralyze people and health systems (Uchôa et al., 2002; BriceñoLeón and Galván, 2007; Avaria and Gómez i Prat, 2008; Jackson et al., 2009; Sanmartino et al., 2015b). It is necessary to promote health rights to increase access to healthcare and social integration. To move forward in addressing Chagas is essential in order to move forward confidently in processes related to health promotion and social participation, which constitute the foundations and sustainability of democratization processes.

In light of the Curitiba Statement on Health Promotion and Equity, in the following pages we will share some fundamental considerations about the current situation of Chagas (rural and in Latin America, as well as the urban and global problem), in order to present reflections that also provide the opportunity to conceive of possible ways of strengthening democracy processes based on human rights. (This Statement represents the voice of researchers, practitioners, social movement members and policymakers who participated in the 22nd IUHPE World Conference on Health Promotion, held in Curitiba, Brazil in May 2016. The Curitiba Statement articulates the recommendations of conference participants and focuses on how strengthening health promotion and improving equity can improve people's lives where ever they live, work, play and learn.)

\section{CHAGAS DISEASE TODAY: REFLECTIONS FROM THE CURITIBA STATEMENT}

We were particularly interested in taking advantage of the central axes addressed in the Curitiba Declaration on Health Promotion and Equity to propose a dialogue allowing the understanding of the current reality of Chagas in the world, the challenges posed by that reality-both rural and urban, and Latin American and global - and the consideration of possible clues that allow us to seek answers and solutions collectively. (The textual fragments of the Curitiba Declaration are italicized.)

For the particular theme that brings us together, our starting point for analysis is the initial statement of the Declaration that particularly stresses that all players involved in the international, national and local arena must try to work together to produce common directions that take into consideration their respective roles. It is from this perspective that we share the following reflections and considerations.
We urge international organizations to recognize that

1. Austerity causes inequity: Health is a buman right and should not be treated as a commodity.

2. A social and economic system that accelerates capital accumulation and results in extreme wealth concentration is inconsistent with achieving equity goals.

3. Many people live in a threatening and hostile environment; and there is a need to work toward the elimination of those corporate and work practices that harm health, damage the environment and compromise social cohesion.

4. They have a role in advocating for the implementation and enforcement of progressive income tax policies to address health equity and strengthen the role of the State in promoting social policies.

In the current world scenario, both the lack of access to timely, comprehensive and quality care and the central aspects highlighted in the first points of the Curitiba Declaration (inequality, mercantilism, hostile environments and threatening environments), pose an obvious call for attention. International organizations, either directly related to the health of populations or indirectly linked to different aspects of people's health and their environments, have a key role: beyond all biomedical aspects that should be reviewed, there are countless elements belonging to other spheres and dimensions that should be also taken into account with the same seriousness and rigor. As Ventura-Garcia et al. said, we think there is a paradox: although the importance of social and cultural factors is broadly acknowledged, current approaches to NTDs almost always neglect aspects of the socio-cultural-biological-environmental triad. This results in a narrower understanding of Chagas disease that hampers sustainable prevention and control (Ventura-Garcia et al., 2013).

As an example, through the Programme on control of Chagas disease, WHO has highlighted the need to focus on people affected by Chagas, underlining the negligence associated with the control of the disease, and the implication that affected children, women and men frequently do not have health, work and other dignified living conditions. The affected population continues to lack basic rights, even if $>100$ years ago the disease was already described.

Echoing the call for attention and considering the necessity of going beyond the biomedical components, the WHO Programme on control of Chagas disease decided to add a sixth particular Technical Group (TG) to the five existing groups (including epidemiological surveillance and information systems, transfusional and organ transplantation transmission, screening and diagnosis, congenital 
transmission and case management of congenital and paediatric cases and case management of adult cases).

The TG6 was convened in 2017 to make technical contributions in the area of information, education and communication (IEC) related to the multiple aspects linked to Chagas. This group is made up of 10 professionals from different country origins and disciplines, with wide and varied expertise in the subject. Through a continuous collaboration, they collectively evaluate the Chagas disease situation, considering the particularities of different contexts. They identify priorities and define strategies and methodological proposals to address each of the three IEC elements. In line with the objectives of the WHO Programme on control of Chagas disease this TG intends to promote the comprehensive approach to the problem of Chagas, from the development and dissemination of IEC resources and strategies, submission of recommendations, evaluation of materials and contributing to the agency advising on Chagas disease globally, in the framework of the UN.

In this way, from an interdisciplinary/intersectoral collaboration to a public health approach, the TG6 contributes to the achievement of WHO objectives, taking into account geographical, historical, social, cultural and political characteristics of the places where the problem of Chagas exists. Considering all social actors involved, the TG6 seeks to promote the right to health, the care of individuals, their families and communities, with the belief that it is possible to eliminate or reduce social, structural, subjective and objective barriers that exclude them from the development of a healthy life.

The current members of the TG6 are: Ana Maria de Arruda Camargo, Andrea Avaria Saavedra, Arturo Solari, Cristina Carrazzone, Isabel Claveria Guiu, Jordi Gómez i Prat, María Cristina Parada, Mariana Sanmartino, Mariella Anselmi and Wilson Oliveira Jr. On the part of the WHO, this group has a technical secretary, composed of: Pedro Albajar Viñas and Stephanie Jourdan.

More information about the TG6 can be obtained at: http://www.beatchagas.org/en/

\section{We call for governments at all levels to}

1. Implement policies that promote gender and raciall ethnic equity as a main aim and use evaluation measures that account for distribution across those groups.

2. Recognize that citizen participation in health decisions is a right, not a concession.
3. Use innovative strategies that strengthen and protect the universal right to health and the well-being of the people of the world at all times and especially during any financial crisis.

4. Enrich their understanding of the threats that affect vulnerable and marginalized populations.

5. Demonstrate better and more transparent use of politics and power.

At the beginning of the twentieth century, Carlos Chagas and Emmanuel Dias already described the reality in which the Chagas problem is situated and thrives, as well as the importance of governments in implementing the required elements for its improvement: rather than technical innovations, the definitive overcoming of human Chagas disease implies, above all, political will and social responsibility (Dias, 1997). In this regard, $>100$ years ago Carlos Chagas himself wrote: There is a nefarious plot in the study of trypanosomiasis. Each work, each study, points a finger towards a malnourished population that lives in bad conditions; It points to an economic and social problem, which gives the rulers tremendous frustration because it is a testimony of inability to solve a tremendous problem (Castagnino, 1986). The validity of these statements is worrisome, especially if we think that this reality has not changed substantially in several existing endemic areas. When analysing the problem, the indispensable consideration of social determinants must be understood in each particular context, and in the way they relate to structural (global) inequalities in which people live. These determinants are perpetuated regularly, despite improvements in the population living conditions (Vim-Kim and Peschard, 2003).

It is also vital to consider that the reality of the disease is complicated by the current globalized context and high human mobility. To improve these strategies prior to implementation, these complexities must be described, deeply analysed and differentiated according to ethno-racial characteristics, gender, age and class (human determinants are frequently combined in processes of social exclusion). In this regard, Ramos and Sousa have pointed out that for the next 30 to 40 years, Chagas disease will still require the attention of governments, even if its transmission could be interrupted now, because of the burden of those with infection (Ramos and Sousa, 2017). At present, we will have to broaden our understanding of the problem of Chagas, going beyond the one restricted to certain areas traditionally considered 'endemic' and presenting the diverse and particular characteristics associated with the presence of humans in different geographical contexts. 
The first forms to understand the problem, exclusively associated with rural contexts of the American continent, should have been overcome. In the 1930s and 1940s, that understanding served as the basis for the control approaches in Argentina, Brazil and Venezuela, for instance, where the focus was placed on the chemical control of the disease vectors. Then, in the second half of the century, because of migratory movements from rural areas to urban centres, the issue settled in health services of large cities. In the 1980s and 1990s, with the so-called 'urbanization of Chagas disease', the problem was opened up to other institutions and actors, including blood banks, hospitals, universities and research centres, with many national and international programmes of control entering the scene at this point (Sanmartino et al., 2015a).

Latin American countries, based on the accumulated experience and the pressure made by regional initiatives, managed to implement vectorial control programs at the subregional level, together with the Pan American Health Organization/WHO. The first of these initiatives was the Southern Cone Initiative to control and eliminate Chagas disease (INCOSUR), created in 1991. Throughout the 1990s and 2000s, following the guidelines set by the INCOSUR strategy, other subregional initiatives were born in different countries of Latin America (Sanmartino et al., 2015a).

However, the geographical borders within which the disease occurred historically were broken, challenging historical and modern scenarios to assume an updated and more impactful approach. Rural-urban migration did not only occur within countries-affected populations also migrated to cities in other countries and other continents. This migration has resulted in the presence of Chagas disease in immigrant populations in countries where the disease is unknown, posing the challenge to countries of destination to think about forms of inclusion and access to health rights. In addition, it is vital to understand the constructs of inequality based on class and ethnic origins in American societies of origin, where the indigenous population has been historically affected and excluded (Briceño-León and Galván, 2007; VelardeRodríguez et al., 2010, Ventura-Garcia et al., 2013).

In this scenario, it is essential to maintain and strengthen the programmes of vector surveillance and control, at the same time that implementing coordinated actions both within and between countries, where people with experience can inform those involved with healthcare and disease control about the approach is urgent. These collaborations should go beyond the health sector, and ideally involve other sectors of the society and all levels of administration, municipality, state and federal government. That is, the need for a joint approach to a health problem that has a clear impact on societies of origin and destination. This should be translated into policies that not only include access strategies, but also control and transformation of sanitary practices of exclusion/non-recognition of the population in need of healthcare (Avaria and Gómez i Prat, 2008; VenturaGarcia et al., 2013; Avaria, 2014). The increase in mobility of people affected should entail a joint commitment of governments in the construction of protection policies and the implementation of universal healthcare systems that protect citizens. Currently, the protection of ethnic and gender equity is indispensable, given that women are frequently the ones who migrate the most and ethnic origin is strongly associated with experiences of discrimination and exclusion in the access to health.

\section{We recognize that the Health Sector should}

1. Be ready to learn from other sectors.

2. Design effective health promotion policies and increase investments in the capacity of health promotion systems to implement them.

3. Advocate recognition by other sectors of the impact their policies have on human health and well-being, affecting mainly vulnerable populations.

As mentioned, Chagas disease presents specific psychological, social and cultural characteristics and determinants for affected people, their families and society in general. Moreover Chagas is nowadays presented in a more complex way, in wider scenarios (from rural and regional to urban and global scopes), involving a wide diversity of actors. In this context, the diagnosis has important repercussions, from psychological, social and cultural points of view. According to recent studies, the affected people often do not want to know if they are infected due to fear of the disease and its imagined consequences (Sanmartino et al., 2015b). This attitude is most commonly derived from previous experiences with relatives or friends, including negative treatment experiences (either because of adverse reactions or barriers to quality healthcare) or death, reinforced by popular beliefs and negative representations of Chagas disease (Avaria and Gómez i Prat, 2008, Velarde-Rodríguez et al., 2010, Avaria 2014).

Likewise, with particular characteristics in different contexts, there are important administrative, social and cultural barriers that hinder prompt attention to a large number of affected people (Monge-Maillo and LópezVélez, 2017). These barriers are reinforced when migration is penalized or prosecuted, which has a direct impact on the conditions deployed in health systems and 
available to these populations. The social production of alterization that places the other as illegitimate, therefore excluded in their rights (Liberona, 2017), is accentuated in situations in which people are represented as a danger to the health of the population for 'importing' diseases. In addition, people who are migrants frequently do not recognize health systems as guarantors of their rights. Instead, health systems are often represented as part of the control mechanisms linked to security and police systems. All of that increases the conditions of vulnerability, stigmatization and illegitimacy attributed to migrants affected by Chagas disease (Avaria, 2014, Liberona, 2017).

From the health sector, prejudices associated with Chagas stereotypes are frequently repeated, including the association between rurality and poverty (Sanmartino et al., 2018) or between migration and contagious diseases (Avaria, 2014). Prejudices increase in migratory contexts, where representations are built around the notions of 'underdevelopment', 'precariousness', 'poverty', 'danger' and processes in which the state and society either do not recognize migrant subjects or violate their rights frequently (Thayer et al., 2013). The prejudices increase attitudes of blame and stigmatization toward the people affected by Chagas, preventing the investigation of the underlying causes that lead to the persistence of the problem.

From that unsympathetic vision, where hegemonic logics of knowledge-power prevail, the experience of others is not recognized and the value of the traditions, habits and practices of groups of affected people is not understood and in many cases despised. The hegemony installed in the health sector is frequently from a collective 'we' that has been constructed as the only legitimate actor to develop strategies and actions to deliver solutions that can improve the lives of affected people (Menéndez, 2003; Avaria, 2014; Padilla Velázquez, 2014; Sanmartino et al., 2015b, 2018; Claveria Guiu et al., 2017). Nevertheless, it is essential to prevent the disease from leading to exclusion and stigmatization, as well actively attempt to de-stigmatize and transform a defeatist vision and promote access to care and social integration (Uchôa et al. al., 2002; Avaria and Gómez i Prat, 2008). Likewise, we believe that this 'rethinking' of the healthcare approach must be built, indisputably, on the contributions not only from the biomedical sciences, but also from the social sciences to achieve a truly comprehensive approach that considers the elements of all dimensions that characterize the problem. This approach implies a joint search, from biological, environmental, social, political and also cultural and spiritual perspectives about contents, methodologies, policies, etc., that allow a carefully considered construction of knowledge and interventions.
This can only make sense if the affected people become a critical and committed part of the whole process.

In response to these considerations, in recent years some groups have sought innovative approaches, to improve healthcare and rights linked to Chagas. Positive experiences have been reported, incorporating biomedical, psychological, social, cultural and anthropological components, and even promoting the elimination of stigmas and social and institutional barriers (Jackson et al., 2009; Sanmartino et al., 2015b; Claveria Guiu et al., 2017). The improvement of access to the health system, in the particular case of a silent and silenced disease, such as Chagas, can only be achieved with comprehensive strategies that address all the actors involved (Uchôa et al., 2002; Velarde-Rodríguez et al., 2010; Basile et al., 2011; Sanmartino et al., 2015a).

Finally, with regard to the Health Sector, we believe that analysing Chagas disease through the migratory and urbanization phenomena allows for the possibility of resituating it in an international context, beyondbut without underestimating-the traditional rural and Latin American borders. We understand the urgent need to implement health promotion strategies that consider the subject as a public health issue, from a human rights perspective, not only at the national and regional levels, but also globally. Thus, Chagas becomes a paradigmatic example of the challenges posed to public health by current geographical changes and globalization (Coura and Viñas, 2010).

\section{We advocate that citizens should be invited to}

1. Engage in critical reflection about their role as active participants in the exercise of citizenship.

2. Exert their great transformative potential in mobilizing and advocating to local authorities the case to put health equity on their agendas-in all policies.

Expanding the social participation of people affected by Chagas disease is a key strategy for overcoming stigma, depression and fear of death, as well as strengthening empowerment, self-esteem and self-care. However, it is not only the responsibility of people and social organizations, but also challenges the States through their governments, since they are the ones that must guarantee various forms of social participation.

Although participation is currently considered a constituent part of the processes of construction of social policies and their implementation, there is a risk of reducing it to the simple validation of certain institutional strategies. These strategies are usually functional to the system, or limit participation to the manifestation of people's opinion regarding issues that are defined from the 
institutional framework. The participation that questions the structures of power and knowledge allows the legitimization of inclusive processes, elaborated from diverse actors, in and from their experiences and knowledge. In this framework, thinking about participation in relation to Chagas disease implies a deep reflection on the structural mechanisms that sustain practices of inequality and social exclusion. The participation of actors who are capable of questioning the status quo and proposing a critical look of the reconfiguration of power relations, where the vulnerable populations are present and where the social actors can be resituated, is indispensable.

We agree with Ramos and Sousa when they argue (Ramos and Sousa, 2017) that besides the necessity of linking the best available evidences and recommendations, we also emphasized the importance of ensuring the legitimate participation of people affected by the neglected diseases throughout the development process. A critical position provides the opportunity to face Chagas disease from the rights perspective, and directly involve the actors as historical subjects who live, construct and transform reality. In order to achieve this, it will be essential not to reduce the participation of social organizations to the mere facts of the disease, but go much further in order to understand it in a social and historical framework that questions and transforms the relations of power and social inequality, which is prevalent across national borders. This approach allows us to be open to the complexity of this reality and to understand Chagas from an approach that involves other areas of people's life (work, social rights, housing, politics, citizenship, etc.).

According to Médecins Sans Frontières' approach (2012), when associations are created, the main motivations and fundamental objectives are those related to information and the recognition of affected people. Additionally, the construction of strategies that outline the demand on local governments to guarantee access to health services are important, and should be based on the empowerment of affected people and the consequent support for the aforementioned processes. Particularly, we emphasize

the strengthening of the protagonism of the affected people: encouraging the members of the organizations to fight for their rights and have an active voice to face the difficulties imposed by the policies and by the disease; participate in decision making, seminars, meetings, congresses, etc. [...] the affected people conquer the capacity of mobilization in favour of better access to health services, guarantee of medicines and possibilities of better therapeutic proposals and control and prevention, among others (MSF, 2012).
This exercise in citizenship and social participation should take into account a broad perspective that encompasses the complexity of Chagas disease, and at the same time recognizes its social, environmental, economic and political determinants that are relevant to the health problems of the population. We also agree with the MSF (2012) proposal that various organizations, together, can strengthen the individual voice of the affected people. The collective voice increases the strength of the struggle for the defense of violated rights.

This participation is complex, puts skills at stake and recreates and reconfigures the history of this population. Therefore, the social organization of people affected by Chagas should be structured around the challenge of transcending the needs of the disease in particular, so they can be placed in context of social rights, from a broader perspective. We emphasize the importance of critical participation, to discuss and reflect on the exercise of power that is (re)produced in social and institutional relations directly and indirectly linked to Chagas, even within social organizations themselves.

From a rights perspective, the main challenge linked to the mobility of people with Chagas, including stigma and prejudice, is the need to guarantee labour rights. The change in the perception that society has about this problem and the actions that aim to prevent affected people from being defined from the disease and, therefore, socially excluded, are crucial. Thus, the first step to strengthen this movement is to reinforce the dialogue between the associations, formed in different neighbourhoods, cities, states and countries, and representatives of the various actors linked to the problem.

With this horizon, in October 2010, the International Federation of Associations of People Affected by Chagas Disease (FINDECHAGAS), was created, comprised of social organizations that face the problem in different parts of the world. It is a non-profit organization, whose main purpose is the creation, promotion and dissemination of the principles and guidelines set forth in the Uberaba Declaration written in the first meeting of associations of people affected by Chagas disease in the Americas, Europe and Western Pacific, held on October 2009 in the city of Uberaba (Minas Gerais, Brazil).

\section{We encourage health professionals and researchers to}

1. Adopt new processes to achieve effective social participation, inclusion, intersectoral action and interdisciplinary approaches.

2. Recognize that the practice of health promotion is influenced directly and indirectly by politics and ideologies. 
3. Use evidence as an instrument for positive social change. We need a science that is both compassionate and culturally sensitive.

4. Play a key role, through the use of effective interventions, in creating a supportive environment and working and living conditions that help ensure the people with whom they work can increase control and influence over the determinants of their health.

Facing a subject such as Chagas and addressing the issue from an integrative perspective, both the advance in the pending topics and the democratization of the scientific knowledge become urgent needs (Sanmartino et al., 2015a). The same happens with the consideration of humanized and integral care, which contemplates in the same way the biomedical, psychosocial and cultural aspects (Oliveira, 2009).

From one side, we observe that in recent decades the knowledge about Chagas disease has increased considerably thanks to the scientific work carried out in many parts of the world. From the other side and as already mentioned, Chagas disease has traditionally been considered a subject of biological and medical approach, and that has created a profound imbalance between the amount of knowledge accumulated about biomedical aspects, and the relation to social and cultural factors involved. At the same time, we observe that the increase in knowledge (important, but partial) is not correlated with the implementation of prevention and control measures, the augmentation of infected people who received healthcare or the reduction of people at risk of infection. Consequently, it can be stated that there still exists a great distance between the progress made in the academic world and the situation faced by many groups affected by Chagas (Sanmartino et al., 2015a).

In this line of thought, we agreed with Guyot that the reduction from the complexity to the simplicity, the disjunction between the scientific culture and the culture of the humanities, were epistemological operations whose goal was to guarantee the rigor and objectivity of the knowledge, but instead led to the inability to see the entire reality, isolating the objects from their full contexts (Guyot, 2005). Other aspects to be taken into account include a process of continuous adaptation to the new realities, both rural and urban, as well as those arising from the globalization process (Briceño-León and Galván, 2007; Sanmartino et al., 2015b). This requires the incorporation of new perspectives. And, as Morel pointed out (Morel, 1999), this leaves no choice but to be imaginative, flexible and unprejudiced in the selection of the new priorities that will shape the next research agendas, including in a transversal way the political dimension linked to the scientific development in the midst of aspects that could be declared simply biomedical (Sanmartino and Carrillo, 2018).

Chagas constitutes a paradigmatic example in this sense, since we see how the policies of knowledge supported by the fragmentary and simplifying view have led to 'great tragedies' (Guyot, 2005) and demonstrate why it is necessary to carry out a change of mind from the perspective of complexity. As stated by Briceño-León and Galván, the answers that currently have to be developed in this topic can neither be exclusively entomological nor medical, but must be developed in broader health and social contexts, involving the different governmental levels and society in general (Briceño-León and Galván, 2007).

Certainly there is still limited research trying to approach Chagas disease with a social, collective, denatured and denaturing approach, from processes that prioritize the voice of the actors (Amieva, 2013, Ventura-Garcia et al., 2013). Like Sanmartino and Carrillo, we believe that the disciplines included in the vast field of Social Sciences knowledge should begin to build a stronger and more committed link with the problem through studies that address, among other issues, the roles that perform the characteristics, speeches, representations and practices of each actor linked to Chagas, from their different backgrounds (states, universities, scientific community, non-governmental organizations, people affected by Chagas, schools, health centres, population in general, etc.), as well as the relationships established between them (Sanmartino and Carrillo, 2018).

The proposal shared here shows the need to deepen the development of 'innovative strategies' of care, prevention and research. Innovative strategies require reflexivity, not only around the knowledge of certain topics or the type of approach to problems, but also about the practices (care, prevention and research) including the design, operationalization and personal assumptions of researchers and members of health teams (Larouche and Potvin, 2013).

\section{FINAL REMARKS}

Health promotion constitutes a global political and social process that encompasses not only actions aimed directly at strengthening the abilities and capacities of individuals and communities, but also those aimed at modifying social, environmental, economic and political conditions in order to mitigate its impact on public and individual health. It is the process that allows people to increase their control over the determinants of health 
and, consequently, improve it. In this way, assuming a focus on health promotion implies overcoming the vision of the population as a mere passive receiver of assistance, as well as educational and informative programs developed by health professionals. Health promotion, from the rights perspective, plays a key role in the resolution of complex problems such as Chagas, fundamentally creating the possibility of putting into dialogue different knowledge, cultures and lifestyles, seeking respect for diversity and the elimination of stigmatization and social exclusion structures.

Through this text we shared some guidelines to imagine, from the key contributions of an inclusive and transformative Health Promotion based on the rights perspective, a new horizon for the people affected (directly and indirectly) by Chagas disease. We consider that these reflections constitute fundamental contributions for the daily work of all involved actors. For this reason, due to its relevance and wide scope, we want to express as a corollary the final point of the Curitiba Statement:

We further advocate that everyone - International Partners, Governments, Health Sector, Health Professionals, Researchers and Citizens - should recognize:

1. Their influence in changing and eliminating all forms of discrimination and exclusion.

2. The potential and capacity of health promotion throughout the life course.

3. That health promotion goals will only be fully achieved by incorporating these four basic principles: equity, human rights, peace and participation.

As stated by Ramos and Sousa, the control of Chagas disease, as well as other NTDs, includes a broader perspective of human and social development initiatives, with an inclusive perspective (Ramos and Sousa, 2017). For this reason, we agreed with Guyot to call for the development of a new vision of science (Guyot, 2005), allowing the incorporation of complexity, which according to the author, would make it possible to establish other links with nature in the terms of a 'new alliance'. Nevertheless, affirming the need for the 'inclusive perspective', the new alliance has to go beyond the limits of scientific explanations and responses and involve a wide range of sectors and actors. We must bet on an alliance in which men and women recover their status of actors, builders, creators of knowledge and as critical historical subjects. We need an alliance that implies and leads, unfailingly, to a new dialogue between men and women with nature, with other men and other women, and with themselves (Guyot, 2005). We are convinced that a successful road ahead has much more to do with the need to connect and collaborate with all protagonists than simply adhere to the latest advances in biology and medicine.

The study of the reality of the Chagas problem worldwide, through the Curitiba Statement, reveals the challenge of current societies, health policies and health structures and States in general, as guarantors of people's rights. Thus, in a context in which human rights are relativized, where participation is reduced to individual exercises and citizenship is reduced to territories and rights shaped by the market, health promotion is a strategy that allows, today more than ever, the ability to build more solid and stable democracies.

The challenge around Chagas lies in the urgent need to eliminate all forms of discrimination and exclusion, transforming the social elements that reproduce inequalities. Understood in this framework, health promotion will allow us to strengthen and consolidate processes that consolidate democratic and equitable societies, contributing to the welfare of both the population historically neglected, as well as the entire society.

\section{REFERENCES}

Amieva, C. (2013) El Chagas y las Ciencias Sociales: una mirada necesaria para una problemática compleja. La Colmena, 6, 21-37.

Avaria, A. (2014). Un cuerpo vale más que mil palabras. Mujeres y hombres bolivianos en Barcelona. Corporización de la migración. Cuerpo migrante, cuerpo trabajador, cuerpo enfermo. Tesis doctoral. Estudios Avanzados en Antropología Social, Facultad de Geografía e História, Universidad de Barcelona.

Avaria, A. and Gómez i Prat, J. (2008) "Si tengo Chagas es mejor que me muera". El desafío de incorporar una aproximación sociocultural a la atención de personas afectadas por Enfermedad de Chagas. Enferm Emerg Impact Factor, 10, 40-45.

Basile, L., Jansà, J. M., Carlier, Y., Salamanca, D. D., Angheben, A., Bartoloni, A. et al. (2011) Working group on Chagas disease. Chagas disease in European countries: the challenge of a surveillance system. Eurosurveillance, 16, $18-27$.

Briceño-León, R. and Galván, J. M. (2007) The social determinants of Chagas disease and the transformations of Latin America. Memórias do Instituto Oswaldo Cruz, 102, 109-112.

Castagnino, H. (1986) Mazza y la lucha contra el mal de Chagas. Todo es Historia, 41, 8-31.

Claveria Guiu, I., Caro Mendivelso, J., Ouaarab Essadek, H., González Mestre, M. A., Albajar-Viñas, P. and Gómez i Prat, J. (2017) The Catalonian expert patient programme for Chagas disease: an approach to comprehensive care involving affected individuals. Journal of Immigrant and Minority Health, 19, 80-90. 
Coura, J. R. and Viñas, P. A. (2010) Chagas disease: a new worldwide challenge. Nature 465, S6-S7.

Dias, J. C. P. (1997) Present situation and future of human Chagas disease in Brazil. Memórias do Instituto Oswaldo Cruz, 92, 13-15.

Galvez, R. and Irazola, J. (2006) El Árbol de la transformación: manual de metodologías participativas Para agentes de salud comunitaria. Medicusmundi, Buenos Aires.

Guyot, V. (2005) Epistemología y prácticas del conocimiento. Ciencia, Docencia y Tecnología, 30, 9-24.

Jackson, Y., Angheben, A., Carrilero-Fernandez, B., Jansa, J. M. L. V., Jannin, J. and Albajar-Viñas, P. (2009) Prise en charge de la maladie de Chagas en Europe. Expériences et défis en Espagne, Suisse et Italie. Bulletin De La Societe De Pathologie Exotique, 102, 326-329.

Larouche, A. and Potvin, L. (2013) Stimulating innovative research in health promotion. Global Health Promotion, 20, 64-69.

Liberona, N. (2017) Pacientes ilegítimos: acceso a la salud de los indocumentados en Chile. Salud Colectiva, 13, 507-520.

Médecins Sans Frontières. (2012) Movilización Popular y Enfermedad de Chagas. Río de Janeiro.

Menéndez, E. (2003) Modelos de atención de los padecimientos, de exclusiones teóricas y articulaciones prácticas. Ciencia e Saúde Coletiva, 8, 185-297.

Mitra, A. K. and Mawson, A. R. (2017) Neglected tropical diseases: epidemiology and global burden. Tropical Medicine and Infectious Disease, 2, 36.

Monge-Maillo, B. and López-Vélez, R. (2017) Challenges in the management of Chagas disease in Latin-American migrants in Europe. Clinical Microbiology and Infection, 23, 290-295.

Morel, C. (1999) Chagas disease, from discovery to control-and beyond: history, myths and lessons to take home. Memórias do Instituto Oswaldo Cruz, 94, 3-16.

Oliveira, W. Jr (2009) All-around care for patients with Chagas disease: a challenge for the XXI century. Memórias do Instituto Oswaldo Cruz, 104, 181-186.

Ramos, A. N. Jr and Sousa, A. S. (2017) The continuous challenge of Chagas disease treatment: bridging evidence-based guidelines, access to healthcare, and human rights. Revista da Sociedade Brasileira de Medicina Tropical, 50, 745-747.

Padilla Velázquez, R. (2014) Conocimiento epidemiológico de la enfermedad de Chagas por los médicos familiares de la UMF 66 del Instituto Mexicano del Seguro Social. Tesis de Epidemiología, Universidad Veracruzana, México.

Sanmartino, M., Amieva, C., Balsalobre, A., Carrillo, C., Marti, G., Medone, P. et al. (2015a). Hablamos de Chagas.
Aportes para (re)pensar la problemática con una mirada integral. CONICET, Buenos Aires.

Sanmartino, M., Amieva, C. and Medone, P. (2018) Representaciones sociales sobre la problemática de Chagas en un servicio de salud comunitaria del Gran La Plata, Buenos Aires, Argentina. Global Health Promotion, 25, 102-110.

Sanmartino, M., Avaria Saavedra, A., Gomez, I., Prat, J., Parada, C. and Albajar-Viñas, P. (2015b) Que no tengan miedo de nosotros: el Chagas según los propios protagonistas. Interface (Botucatu)—Comunicação, Saúde, Educação, 19, 1063-1075.

Sanmartino, M. and Carrillo, C. (2018) La(s) ciencia(s) y la problemática del Chagas: reflexiones sobre un camino de más de cien años. In Ortúzar, G. (ed), Ética, ciencia y política. Hacia un paradigma ético integral en investigación. Facultad de Humanidades y Ciencias de la Educación (UNLP), La Plata. En prensa.

Thayer, E., Córdova, M. G. and Ávalos, B. (2013) Los límites del reconocimiento: migrantes latinoamericanos en la Región Metropolitana de Santiago de Chile. Perfiles Latinoamericanos, 42, 163-191.

Uchôa, E., Firmo, J. O. A., Dias, E. C., Pereira, M. S. N. and Gontijo, E. D. (2002) Signos, significados e ações associados à doença de Chagas. Cad Saude Publica, 18, 71-79.

Velarde-Rodríguez, M., Avaria-Saavedra, A., Gómez-i-Prat, J., Jackson, Y., Oliveira, W. A. Jr, and Camps-Carmona, B. (2010) Need of comprehensive health care for T. cruzi infected immigrants in Europe. Revista da Sociedade Brasileira de Medicina Tropical, 42, 92-95.

Ventura-Garcia, L., Roura, M., Pell, C., Posada, E., Gascón, J., Aldasoro, E. et al. (2013) Socio-cultural aspects of Chagas disease: a systematic review of qualitative research. PLOS Neglected Tropical Diseases, 7, e2410.

Vim-Kim, N. and Peschard, K. E. (2003) Anthropology, inequality, and disease: a review. Annual Review of Anthropology, $32,447-474$.

World Health Organization (WHO). (2010) Working to Overcome the Global Impact of Neglected Tropical Diseases. First WHO Report on Neglected Tropical Diseases, WHO/HTM/NTD/2010.1. WHO, Genève.

World Health Organization (WHO). (2013) Sustaining the Drive to Overcome the Global Impact of Neglected Tropical Diseases. Second WHO Report on Neglected Tropical Diseases, WHO/HTM/NTD/2013.1. WHO, Genève. 